\title{
A comparative study of health, nutritional status, and dietary pattern of primary school going and dropout slum children in Dhaka City, Bangladesh
}

\author{
Sharmina Yeasmin ${ }^{1}$, Khaleda Islam ${ }^{2}$ \\ ${ }^{1} M S c .$, Student, Institute of Nutrition and Food Science, University of Dhaka, Dhaka, Bangladesh, \\ ${ }^{2}$ Professor, Institute of Nutrition and Food Science, University of Dhaka, Dhaka, Bangladesh
}

Background: Health affects not only current well being and future outcomes at individual and society level but also directly reflect the efficiency of health care system and the influence of surrounding environment. This is especially nutritional status of primary school age children which influence their health, dietary habit, cognition and educational achievement. Aims and Objectives: The purpose of this study was to find and compare between primary school going and dropout slum children (6-12 years) regarding their health, nutritional status and dietary pattern in four selected slums in Dhaka city, Bangladesh. Materials and Methods: It was a descriptive cross-sectional study conducted among 100 children. Nutritional status was measured by collecting anthropometric data (height and weight) using standard techniques and analyzed according to WHO guidelines. Results: Based on WHO standard mean of Body Mass Index (BMI), the prevalence of underweight was higher among school dropout group (76\%) than school going group (54\%). A statistically significant difference between two groups were found regarding prevalence of stunting ( $P$-value $=0.03$ ) and their daily dietary habits, such as, pulses $(P$-value $=0.007)$, rice, fruits, milk, and meat $(P$-value $=0.00)$ and fish $(P$-value $=0.002)$. This study also found that parent's education, family size, mother's occupation, and economic status of family have an important impact on children's education and their nutritional status. Conclusion: Low education levels are linked to poor health and low quality dietary pattern. Lower socioeconomic condition and poor knowledge of parent's about child education and nutritional diet makes this situation more worse.

Key words: Primary school age children, Slum, Educational status, Malnutrition, Dietary habits

\section{INTRODUCTION}

The nutritional status of children in slum of Dhaka city is a sensitive indicator of health, economy and sustainable development of Bangladesh. ${ }^{1}$ Around 3.4 million people live in slum in Dhaka and the number are increasing due to rural-urban migration. Most slums are illegal and so those are not provided with government services including education. Children living in slums also have very limited
Access this article online

\section{Website:}

http://nepjol.info/index.php/AJMS

DOI: 10.3126/ajms.v7i4.14558

E-ISSN: 2091-0576

P-ISSN: $2467-9100$ access to government school elsewhere and schools are often very poor quality. ${ }^{2}$

According to a UNICEF's report on the state of the world's children, most of urban poor slum children don't go to school. Instead, they often work in dangerous or exploitative jobs. The report also mentioned that, around 115 million of the world's children work in hazardous job. ${ }^{3}$ Moreover, the dropout rate in Bangladesh for both boys and 
girls increased from 33\% in 2002 to $47 \%$ in 2006, according to baseline survey on primary education conducted by the Directorate of Primary Education (DPE). ${ }^{4}$

Nutritional deprivation is rampant in children of school age, particularly primary school age children ranging in magnitude from $20 \%-80 \%$. Since deficient physical growth is naturally reflected in their suboptimal mental development. ${ }^{5}$ Malnutrition, which refers to an impairment of health either from a deficiency or excess or imbalance of nutrients is the public health significance among children all over the world especially in developing countries. ${ }^{6,7}$

In one of the largest studies in anthropometric status of school age children in low income countries like Bangladesh found the overall prevalence of stunting and underweight to be high, ranging from $48 \%$ to $56 \%$ for stunting and $34-62 \%$ for under weight. It is therefore evident that a significant percentage of school age children suffering from malnutrition, which affecting their health, nutritional status and school academic performance. ${ }^{8}$ The situation is worsened because slum dwellers are exposed to poor environmental condition (i.e., overcrowding, poor quality drinking water, sanitation, and no removal of waste), low health care use, poor diet, and lack of nutritional knowledge.

Malnutrition not only makes the child more vulnerable to morbidity and mortality ${ }^{9,10}$ but has been linked to poorer educational attainment, ${ }^{11}$ lower intellectual and physical abilities in adult life. ${ }^{12}$ Recent studies of the national level found a high prevalence of malnutrition among school age children in slums. It was also found that school dropout children are also increasing at an alarming rate. Hence this study was undertaken to assess and compare health, nutritional status, dietary pattern and living environment of school going and school dropout slum children in Dhaka city.

\section{MATERIALS AND METHODS}

The present descriptive cross sectional study was conducted in the four selected slum area of Dhaka City, which focused on the health and nutritional status of slum children aged 6-12 years old. To determine the sample size two stage purposive random sampling techniques were adopted. At first, four study locations were randomly selected, namely Kamlapur, Kawran Bazar, Lalbagh and Kalimondir slum area. Secondly, 25 individuals in each location were included in the study by purposive random sampling method making a total of 100 children (50 school going and 50 school dropout). The purpose and nature of the study were explained to the participants and their families, and after verbal consent they were recruited to the study.
The data were collected by interviewing and examining the participants with the help of their guardian.

Nutritional status was assessed by anthropometric measurement that is measuring weight and height. During the measurement of weight each subject was asked to be barefooted and removed heavy cloths to record the data in $\mathrm{kg}$ by using standard weighing machine. For measuring the height the subjects were requested to stand barefooted on the platform of a wooden Stadiometer with their head upright and looking straight forward, so that, the shoulders, the buttocks and the heels touch the vertical measuring board. Height was measured to the nearest $0.1 \mathrm{~cm}$. WHO reference values were used to compare the difference in the prevalence of underweight and stunting among children from school going and school dropout child by considering Body Mass Index (BMI) and Height for age (HAZ) Z-Score. ${ }^{13}$ Dietary habits have been studied depending on the consumption of foods by using a food frequency checklist of locally available common foods.

Data were entered and analyzed by using SPSS 19 and ENA. Qualitative data were presented as frequency and percentage. Shapirowiki test was used to determine whether quantitative variables are parametric or nonparametric to choose the appropriate test of significance. Quantitative variables were presented as mean, minimum, maximum, standard deviation and percentiles. Parametric variables and nonparametric variables were compared between studied groups using independent sample t-test and Mann-Whitney $U$ test, respectively. Chi-square test and Fisher exact test were used to compare categorical variables between studied groups.

\section{RESULTS}

The present study recruited a total of 100 slum children, 50 of them belonged to primary school going and 50 belonged to the school dropout category. Table 1 depicts the socio demographic profile in which statistically significant differences were found between two studied groups regarding their age and their employment status.

A majority of dropout children (94\%) had jobs to support their family as only $20 \%$ school going children were involved in the job. Concerning the parent's educational level, the difference between two studied groups were highly statistically significant $(\mathrm{P}$-value $=0.00)$. Most of the parents of the school going children had completed primary level education which is higher than parents of dropout children.

As for the family size, the families of the most school going participants $(66 \%)$ were contained less than 5 members, 
while majority of families of dropout children (60\%) were ranged between 5-8 people. A highly statistically significant difference was found between two studied groups in terms of mother's occupation. Most of the school dropout participant's mothers were housewives (48\%) compared to $10 \%$ in school going group. On the other hand, a good portion of school going children's mother were daily labor $(56 \%)$ and garment worker (34\%). No statistically significant differences were found between two groups regarding sex and household head.

\begin{tabular}{|c|c|c|c|c|c|}
\hline \multirow[t]{3}{*}{ Variable } & \multicolumn{4}{|c|}{ Category of children $(n=50)$} & \multirow[t]{3}{*}{ P-value } \\
\hline & \multicolumn{2}{|c|}{ School going } & \multicolumn{2}{|c|}{ Dropout } & \\
\hline & No & $\%$ & No & $\%$ & \\
\hline Age (Mean $\pm S D)$ & \multicolumn{2}{|c|}{$9.62 \pm 1.6$} & \multicolumn{2}{|c|}{$10.34 \pm 1.5$} & 0.22 \\
\hline \multicolumn{6}{|l|}{ Sex } \\
\hline Male & 34 & 68 & 32 & 64 & \multirow[t]{2}{*}{0.673} \\
\hline Female & 16 & 32 & 18 & 36 & \\
\hline \multicolumn{6}{|l|}{ Family size } \\
\hline$<5$ & 33 & 66 & 16 & 32 & \multirow[t]{3}{*}{0.03} \\
\hline $5-8$ & 15 & 30 & 30 & 60 & \\
\hline$>8$ & 2 & 4 & 4 & 8 & \\
\hline \multicolumn{6}{|l|}{ Do have you any job? } \\
\hline Yes & 10 & 20 & 47 & 94 & \multirow[t]{2}{*}{0.00} \\
\hline No & 40 & 80 & 3 & 6 & \\
\hline \multicolumn{6}{|l|}{ Father's education } \\
\hline Illiterate & 13 & 26 & 42 & 84 & \multirow[t]{3}{*}{0.00} \\
\hline Only signature & 11 & 22 & 5 & 10 & \\
\hline Primary level & 26 & 52 & 3 & 6 & \\
\hline \multicolumn{6}{|l|}{ Mother's education } \\
\hline Illiterate & 15 & 30 & 43 & 86 & \multirow[t]{3}{*}{0.00} \\
\hline Only signature & 15 & 30 & 5 & 10 & \\
\hline Primary level & 20 & 60 & 2 & 4 & \\
\hline \multicolumn{6}{|l|}{ Household head } \\
\hline Father & 43 & 86 & 35 & 70 & \multirow[t]{2}{*}{0.09} \\
\hline Mother & 7 & 14 & 15 & 30 & \\
\hline \multicolumn{6}{|l|}{ Mother's occupation } \\
\hline Daily labor & 28 & 56 & 20 & 40 & \multirow[t]{3}{*}{0.00} \\
\hline Housewife & 5 & 10 & 24 & 48 & \\
\hline Garments worker & 17 & 34 & 6 & 12 & \\
\hline
\end{tabular}

\begin{tabular}{|c|c|c|c|c|c|}
\hline \multirow[t]{3}{*}{ Variable } & \multicolumn{4}{|c|}{ Category of children } & \multirow[t]{3}{*}{ P-value } \\
\hline & \multicolumn{2}{|c|}{ School going } & \multicolumn{2}{|c|}{ Dropout } & \\
\hline & $\mathbf{N}$ & $\%$ & $\mathbf{N}$ & $\%$ & \\
\hline \multicolumn{6}{|l|}{ Height for age } \\
\hline Severely stunting $(<-3 \mathrm{SD})$ & 2 & 4 & 5 & 10 & 0.03 \\
\hline $\begin{array}{l}\text { Moderately stunting } \\
(<-2 \text { SD to } \geq-3 \text { SD) }\end{array}$ & 19 & 38 & 34 & 68 & \\
\hline Normal (-2 SD to+2 SD) & 29 & 58 & 11 & 22 & \\
\hline \multicolumn{6}{|l|}{ BMI } \\
\hline Underweight $(<18.5)$ & 27 & 54 & 38 & 76 & 0.01 \\
\hline Normal ( 18.5 to 24.99$)$ & 21 & 42 & 12 & 24 & \\
\hline Overweight $(\geq 25)$ & 2 & 4 & 0 & 0 & \\
\hline
\end{tabular}

As observed from Table 2, concerning the anthropometric measurements majority of school dropout children (76\%) were considered underweight compared to $54 \%$ of school going children. Moreover, the prevalence of moderate and severe stunting was significantly higher among school dropout children than school going group ( $\mathrm{P}$-value $=0.03)$.

Regarding the daily food consumption (Table 3), there were statistically significant differences between two participated groups concerning daily consumption of pulses (P-value $=0.007)$, rice, fruits, milk, and meat $(\mathrm{P}$-value $=0.00)$ and fish $(\mathrm{P}$-value $=0.002)$.

As illustrated in Table 4, higher percentage of school going participants a take bath $(90 \%)$, toothbrush $(84 \%)$, and

\begin{tabular}{|c|c|c|c|}
\hline \multirow{2}{*}{$\begin{array}{l}\text { Foods } \\
\text { item }\end{array}$} & \multicolumn{2}{|c|}{ Mean $\pm S D$} & \multirow[t]{2}{*}{ P-value } \\
\hline & School going & Dropout & \\
\hline Rice & $6.86 \pm 0.7$ & $6.04 \pm 1.7$ & 0.00 \\
\hline Bread & $3.7 \pm 1.3$ & $2.7 \pm 1.5$ & 0.001 \\
\hline Pulses & $4.9 \pm 1.01$ & $4.4 \pm 1.00$ & 0.007 \\
\hline Fruits & $1.2 \pm 0.7$ & $0.5 \pm 0.13$ & 0.00 \\
\hline Vegetables & $5.5 \pm 1.01$ & $5.2 \pm 1.4$ & 0.37 \\
\hline Milk & $0.5 \pm 0.3$ & $0.3 \pm 0.8$ & 0.00 \\
\hline Egg & $0.6 \pm 0.4$ & $0.6 \pm 1.04$ & 0.54 \\
\hline Meat & $1.4 \pm 0.3$ & $1.01 \pm 0.5$ & 0.00 \\
\hline Fish & $1.2 \pm 0.5$ & $0.9 \pm 0.5$ & 0.002 \\
\hline Oil & $6.8 \pm 0.4$ & $7.0 \pm 0.00$ & 0.04 \\
\hline Sugar & $2.6 \pm 1.2$ & $2.5 \pm 1.01$ & 0.77 \\
\hline
\end{tabular}

\begin{tabular}{|c|c|c|c|c|c|}
\hline \multirow[t]{3}{*}{ Variable } & \multicolumn{4}{|c|}{ Category of children } & \multirow[t]{3}{*}{ P-value } \\
\hline & \multicolumn{2}{|c|}{ School going } & \multicolumn{2}{|c|}{ Dropout } & \\
\hline & No & $\%$ & No & $\%$ & \\
\hline Hand wash before meal & & & & & 0.27 \\
\hline Yes & 48 & 96 & 44 & 88 & \\
\hline No & 2 & 4 & 6 & 12 & \\
\hline Take bath regularly & & & & & 0.00 \\
\hline Yes & 45 & 90 & 20 & 40 & \\
\hline No & 5 & 10 & 30 & 60 & \\
\hline Teeth brush regularly & & & & & 0.00 \\
\hline Yes & 42 & 84 & 11 & 22 & \\
\hline No & 8 & 16 & 39 & 78 & \\
\hline Clean cloth regularly & & & & & 0.00 \\
\hline Yes & 31 & 62 & 6 & 12 & \\
\hline No & 19 & 38 & 44 & 88 & \\
\hline Toilet facilities & & & & & 0.17 \\
\hline Open & 1 & 2 & 4 & 8 & \\
\hline Temporary & 9 & 18 & 19 & 38 & \\
\hline Sanitary & 40 & 80 & 27 & 54 & \\
\hline Wash hand after toilet & & & & & 0.04 \\
\hline Yes & 49 & 98 & 40 & 80 & \\
\hline No & 1 & 2 & 10 & 20 & \\
\hline Cutting nail regularly & & & & & 0.00 \\
\hline Yes & 38 & 76 & 7 & 14 & \\
\hline No & 12 & 24 & 43 & 86 & \\
\hline
\end{tabular}


clean cloth $(62 \%)$ regularly, which is higher than dropout children $(40 \%, 22 \%$, and $12 \%)$. Almost all of the school going respondents $(98 \%)$ said they wash their hands after coming from toilet compared to $80 \%$ of dropout children who gave positive answer, but no statistically significant difference was found between two groups concerning toilet facilities.

\section{DISCUSSION}

The foundation of good health and sound mind are laid during the school age period. ${ }^{14}$ The school has been identified as a suitable place to implement nutrition education programs, because it has a systematic environment. ${ }^{15}$ But in Bangladeshi slum the school dropout is increasing at an alarming rate. According to baseline survey on primary education conducted by the directory of primary education (DPE), the dropout rate for both boys and girls increased from $33 \%$ in 2002 to $47 \%$ in $2006 .{ }^{4}$ Hence, the present study was formulated with the objective to determine and compare health, nutritional status and dietary habits of school going (50) and dropout (50) children making a total of 100 slum children (6-12 years of age).

Anthropometric examination is an almost mandatory tool in any research to assess nutritional status in childhood. Based on the age, body weight and height a number of indices such as height for age Z-Score and BMI have been suggested. In this present study the result showed that, there was a statistically significant difference between two studied groups regarding prevalence of stunting $(\mathrm{P}$-value $=0.03)$ and underweight $(\mathrm{P}$-value $=0.01)$. The anthropometric result of study in urban slums of Tangail Pourashava recorded that $28.9 \%$ children were stunted and $69.9 \%$ were normal and only $1.2 \%$ were over normal. ${ }^{16}$ This indicates better conditions of school going children compare to our study, which showed $38 \%$ of school going children were moderately stunted and $58 \%$ were normal. But in dropout group prevalence of stunting was higher $(68 \%$ moderately stunted, $22 \%$ normal and 10\% severely stunted) than school going children. Similarly, the prevalence of underweight was significantly more prevalent in school dropout children $(76 \%)$ than school going children (54\%). This finding was in contrast to the result of a similar study conducted in Peru, which revealed that students with relatively higher height for age Z-Score and BMI in 1998 were more likely to be dropout from school going in $2001 .^{17}$

The study showed majority of dropout children (94\%) had job compared to only $20 \%$ children in the school going group. It has been also found that there was highly statistically significant difference between two studied groups in terms of their parent's educational status. That is parent's lack of knowledge about education is one of the main reasons for children to be dropout. These findings are in accordance with other international studies, ${ }^{18,19}$ which concluded that nutritional status is significantly related to income and educational background of the parents. Family size also influences the nutritional status of children. More than half of the participants from the school going group (66\%) were contained less than 4 members in the family, while major participants from school dropout groups $(60 \%)$ were contained 5-8 members. That is, the nuclear family concept was more adopted in school going children's family. National Family Health Survey (NFHS) 1 also showed that children living in joint families set up were more likely to suffer chronic malnutrition than children in a nuclear family. ${ }^{20}$

The study revealed almost half of dropout children's mothers were a housewife, but most of the mothers of school going children were workers. That means, working mothers have strong positive effects on children's education and their nutritional status. This is, in contrast to another study, which showed children of non working mother had better nutritional status than the working mother. ${ }^{21,22}$

The environment and personal hygiene of the slum children is highly considerable which directly influences their nutritional status. In our present study, no statistically significant difference was found between school going and dropout children in regard to hand washing before meals. The majority of school going children $(96 \%)$ and dropout participants $(88 \%)$ were maintaining these practices. Notably the frequencies of hand washing before meals among children in our study are substantially higher than frequencies reported from studies of the children from the Philippines and Colombia indicated that $75.9 \%$ and $46.9 \%$ of students, respectively, reported washing hands before a meal. ${ }^{23,24}$ The result showed that the difference between two participated groups with respect to take bath, clean cloth, teeth brash regularly and wash hands after toilet were highly statistically significant. That is, school going children in slum area having a good sense of personal hygiene practices than school dropout child. Similar results was found in another study conducted in India. ${ }^{25}$ The majority of school going children (76\%) cut nail regularly compared to $14 \%$ children among school dropout groups $($ P-value $=0.00)$. So, environmental sanitation and hygiene practices have a significant impact (P-value $\leq 0.05)$ on the health of a school going child of the slum. ${ }^{26}$

\section{CONCLUSION}

The study revealed that, the prevalence of malnutrition was higher among school dropout children than school going 
children. It is also showed that parent's education level and socioeconomic condition directly affects children's educational status and health outcomes. As education is a key building of a society that can overcome poverty in a sustainable manner and the quality of future human resources depend on the present day children, improvement of children's schooling and their nutritional level should be given top priority. But we found that in Bangladesh many of the school age slum children have to choose, but help their poverty stricken families and become involved in hazardous work. Moreover, they are deprived of their basic right, such as, education, nutrition and protection. So, the physical and emotional development of children in slums is severely curtailed. Although many of them go to school, they are better than drop out children in many categories, but half of the slum children become school dropout due to poor socioeconomic condition.

\section{REFERENCES}

1. Rahman $\mathrm{MH}$ and Alam SS. Nutritional Status of Children in Slums of Dhaka, Bangladesh. J Nutr Food Sci 2015; 5:6.

2. Cameron S. Education Decisions in Slums of Dhaka. BAICE Conference 2008. Brighton: University of Sussex.

3. World's slum children in desperate need, UNICEF says. http:// latimesblogs.latimes.com/world_now/2012/02/unicef-reportsays-worlds-slum-children-in-desperate-need.html

4. Bangladesh: Gender gap, dropout rate a challenge for schools. http://www.irinnews.org/report/82444/bangladesh-gender-gapdropout-rate-a-challenge-for-schools

5. Fazili A, Mir A, Pandit IM, Bhat IA, Rohul $\mathrm{J}$ and Shamila $\mathrm{H}$., Nutritional Status of School Age Children (5-14 years) in a Rural Health Block of North India (Kashmir)Using WHO Z-Score System. J. Health Allied Sci 2012;11:1-3.

6. Wenyan J, Lin L, Rui L and Na Z. The Current situation of Child and adolescent psychological problems and intervention in China. Asian J Medical Sciences 2016; 7(3):15-17.

7. Sati $\vee$ and Dahiya S. Nutritional Assessment of Rural SchoolGoing Children (7-9 Years) of Hisar District, Haryana. 2012; 1:363.

8. Chesire EJ, Orago ASS, Oteba LP and Echoka E. Determinants of under nutrition among school age children in a Nairobi Periurban slum. East Afr Med J 2008; 85.

9. Fenske N, Burns J, Hothorn T and Rehfuess EA. Understanding child stunting in India: a comprehensive analysis of socioeconomic, nutritional and environmental determinants using additive quantile regression. PLOS One. 2013.

10. Soundarya M, Abhijna S, Pradhum R, Basavaprabhu A, Mukta C and Deepak M. Knowledge, attitude and perceptions of mothers with children under five years of age about vaccination in
Mangalore, India. Asian J Medical Sciences 2014; 5(4): 52-57.

11. Moestue $\mathrm{H}$ and Huttly $\mathrm{S}$. Adult education and child nutrition: the role of family and community. J Epidemiol Community Health 2008;62(2):153-159.

12. Siddiqi $M N$, Haque $M N$ and Goni $M$. Malnutrition of under-five children: Evidence from Bangladesh. Asian J Medical Sciences 2011;2 (2):113-119.

13. WHO Expert Consultation. Appropriate body-mass index for Asian populations and its implications for policy and intervention strategies. Lancet 2014;363(9403):157-163.

14. Srivastava A, Mahmood SE, Srivastava PM, Shrotriya VP and Kumar B. Nutritional status of school-age children - A scenario of urban slums in India. Archives of Public Health 2012; 70:8.

15. Ara R, Hoque SR, Adhikary M, Uddin MN, Mahmood AR and Ferdousi SK. Nutritional status among the primary school children in a selected rural community. J. Dhaka Med. Coll 2011; 20(2): 97-101.

16. MA Haque, MN Haque, MM Sultana, SM Hossen and S Paul. Effect of Water Quality, Environmental Sanitation and Hygiene Practices on Health of School Going Children of Urban Slum Areas. J. Env Sci Natural Res 2015; 8:1.

17. Cueto $\mathrm{S}$. Height, weight, and education achievement in rural Peru. Food Nutr. Bull 2005; 26(2): 251-260.

18. Adegun JA, Ajayi-Vincent $O B$ and Alebiosu EO. Differences in the nutritional status of young school children from public and private owned primary schools in Ekiti state, Nigeria. European Scientific Journal 2013; 9(7).

19. Manandhaar N, Krishna G and Patoway S. Nutritional status of Primary School Children. Journal of Institute of Medicine 2008; 30(2).

20. Srivastava A, Mahmood SE, Srivastava PM, Shrotriya VP and Kumar B. Nutritional status of school-age children - A scenario of urban slums in India. Arch Public Health 2012; 70(1): 8.

21. Gopaldas $T$, Patel $P$ and Bakshi M. Selected socio-economic, environmental, maternal, and child factors associated with the nutritional status of infants and toddlers. Food Nutr Bull 1998;10:29-34.

22. Shah SM, Selwyn BJ, Luby S, Merchant A and Bano R. Prevalence and correlates of stunting among children in rural Pakistan. Pediatr Int 2003; 45:49-53.

23. Turin TC, Rumana $\mathrm{N}$ and Shahana N. Dietary pattern and food intake habit of the underprivileged children residing in the urban slums. Iran J Ped 2007; 17(3):227-234.

24. Vivas A, Gelaye B, Aboset N, Kumie A, Berhane $Y$ and Williamsa MA. Knowledge, Attitudes, and Practices (KAP) of Hygiene among School Children in Angolela, Ethiopia. J Prev Med Hyg 2010; 51(2): 73-79.

25. Vismita P, Paliwal CK, Nishi F and Surbhi C. Personal hygiene habits among school-going children in rural areas of Jaipur, Rajasthan, India. IJSRR 2014; 3(2):126-142.

26. Haque MA, Haque MN, Sultana MM and Hossen SM. Effect of water quality, environmental sanitation and hygiene practices on health of school going children of urban slum areas. J Env Sci Natural Res 2015; 8(1).

\section{Authors Contribution:}

SY - Concept and design of study, collected data, review of literature, manuscript preparation, analysis of data and results, prepared first draft of manuscript, critical revision of manuscript, manuscript editing; KI - Concept and design of study, critical revision of manuscript, manuscript editing.

Source of Support: Nil. Conflict of Interest: None. 